\title{
Tradisi Omed-omedan dalam Perspektif Industri Budaya
}

\author{
I Nyoman Jayanegara \\ STMIK STIKOM Indonesia \\ Email: jayanegara@stiki-indonesia.ac.id
}

\begin{abstract}
The Omed-omedan tradition is one of the unique traditions in the city of Denpasar, precisely in Banjar Kaja, Kelurahan Sesetan. The Omed-omedan tradition is a mythology accepted as a cultural heritage of the Banjar Kaja community, Sesetan, has been passed down from the older generation to the present. That's why this tradition is said to be unique and rare as cannot be found elsewhere. The Omed-omedan tradition was originally a tradition that was carried out spontaneously by the Banjar Kaja community, but in its development it has transformed into a cultural festival which certainly has a fairly high selling value. The transformation of a tradition which was initially carried out spontaneously by the community into a festival showed that the cultural industry with its capitalist ideology was able to influence most people to agree that the implementation of this tradition was packaged into a festival. The Banjar Kaja Sesetan community feels that they need a new model in the implementation of this tradition so that it has more selling value and is better known than before. The Banjar Kaja community, Sesetean, has unconsciously been hegemony by capitalist ideology so that it has unconsciously agreed to transform the tradition from spontaneity into a festival. By reason of the progress of the era and tourism, this tradition is considered to have high economic value so that it should be used as a cultural festival. The cultural industry does not eliminate the sacred value of this tradition, but by turning into a festival with various packages that satisfy the people present, resulting in the loss of the authenticity of the tradition, there has been an unconscious uniformity in the implementation of this tradition.
\end{abstract}

Keywords: Omed-omedan tradition, cultural industry, ideology, capitalism

\section{PENDAHULUAN}

Globalisasi memengaruhi hampir setiap aspek kehidupan manusia, tidak terkecuali dengan aspek budaya. Menurut Kroeber dan Kluckholm dalam Sutrisno dan Hendar Sutanto (2005: 8), kebudayaan dilihat dari definisi genetis di mana definisi ini melihat asal-usul bagaimana budaya bisa eksis atau tetap bertahan, definisi ini cenderung melihat budaya lahir dari interaksi antar manusia dan tetap bisa bertahan karena ditransmisikan dari satu generasi ke generasi selanjutnya. Jika dilihat pengertian tersebut dapat diartikan bahwa kebudayaan merupakan sebuah nilai-nilai yang dianut oleh sebuah masyarakat. Nilai-nilai yang dikatakan adiluhung ini secara tidak sadar terwarisi secara turun temurun tanpa pernah melakukan sebuah bantahan atau pertanyaan.

Bali yang merupakan salah satu destinasi wisata dunia sudah barang tentu memiliki sebuah bentuk kebudayaan yang unik dan menarik. Masyarakat Bali yang agraris telah menghasilkan kebudayaan yang memiliki nilai-nilai seni tinggi namun dengan pengaruh pariwisata dan globalisasi, beberapa hasil-hasil kebudayaan 
mengalami transformasi. Transformasi dari hasil-hasil kebudayaan ini bahkan mampu menghilangkan nilai-nilai kesakralan menjadi seni profan.

Globalisasi secara tidak sadar telah mempengaruhi sudut pandang orang Bali tentang kebudayaannya. Tradisi yang merupakan salah satu bentuk hasil kreatifitas dan ekspresi masyarakat agraris berusaha diberikan nilai ekonomis dengan alasan sebagai salah satu bentuk suguhan kepada wisatawan. Sudah barang tentu dengan nilai-nilai ekonomis inilah beberapa tradisi secara tidak sadar mengalami penyeragaman. Penyeragaman-penyeragaman ini sudah barang tentu menghilangkan autentisitas sebuah tradisi.

Terkait dengan hal di atas, salah satunya adalah tradisi Omed-omedan di Banjar Kaja, Kelurahan Sesetan, Denpasar. Tradisi ini merupakan salah satu bentuk hasil kreatifitas masyarakat agraris, di mana biasanya masysrakat agraris akan melakukan pertunjukan kebudayaan sebagai pengisi waktu luang selepas panen, atau bahkan tradisi merupakan salah satu bentuk persembahan kepada Tuhan atau pemimpin wilayah. Tradisi Omed-omedan pada awalnya adalah sebuah tradisi yang dilakukan secara spontanitas oleh masyarakat banjar Kaja, namun dalam perkembangannya telah bertransformasi menjadi sebuah festival budaya yang tentunya memiliki nilai jual yang cukup tinggi. Dalam artikel ini akan dibahas mengenai tradisi Omed-omedan itu sendiri disertai dengan pembahasan dengan sudut pandang industri budaya.

\section{TRADISI OMED-OMEDAN}

Tradisi Omed-omedan merupakan salah satu tradisi unik di Kota Denpasar, tepatnya di Banjar Kaja, Kelurahan Sesetan. Seperti yang diungkapkan oleh Munggah (2008: 4), tradisi Omed-omedan adalah sebuah mitologi yang diterima sebagai warisan budaya masyarakat Banjar Kaja , Sesetan secara turun- temurun dari generasi tua sampai saat ini. Karena itulah tradisi ini dikatakan unik dan langka, sama sekali tidak ada ditempat lain. Tidak hanya itu, dalam perkembangannya tradisi Omed-omedan juga telah

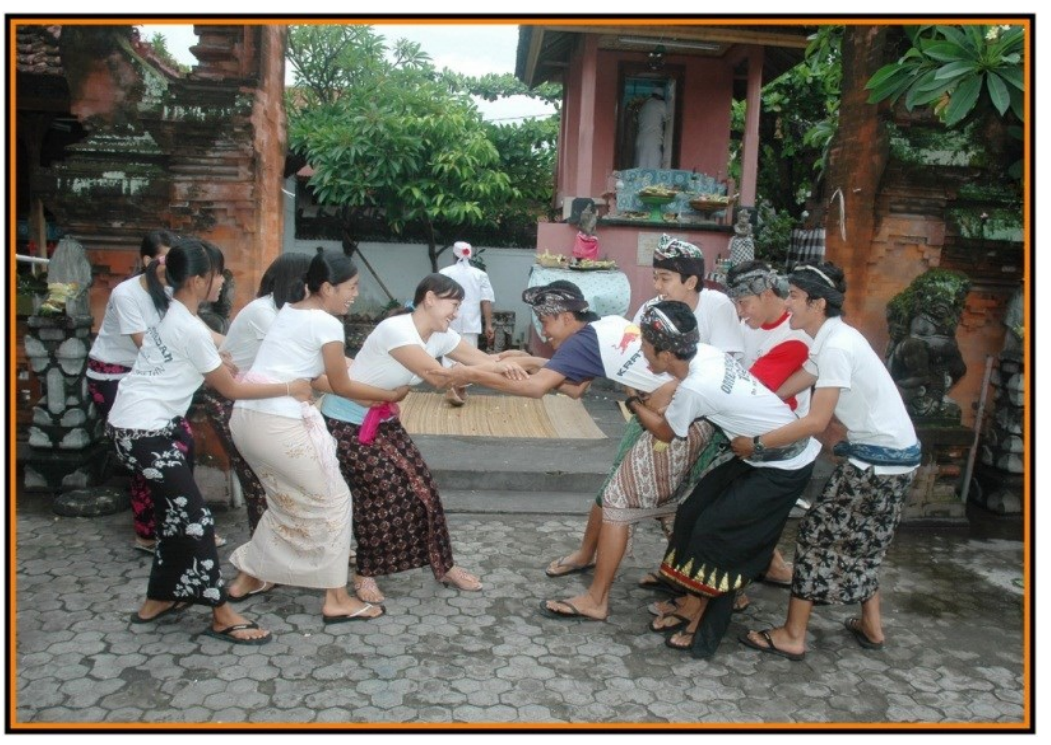

Gambar 1. Visualisasi Tradisi Omed-omedan Sumber: repro Made Munggah mengalami beberapa perubahan, yaitu; waktu pelaksanaan yang berganti, perbaikan nama, sampai dengan bentuk pelaksanaannya.

Pelaksanaan tradisi Omed-omedan adalah sebuah aktivitas yang telah dilakoni oleh masyarakat Banjar Kaja sebagai sebuah bentuk pelestarian budaya. Tradisi ini telah berlangsung secara tradisional dan tidak diketahui kapan dimulainya. Pelaksanaan tradisi yang telah berlangsung secara turun temurun ini hanyalah sebuah permainan yang bersifat spontanitas oleh masyarakat Banjar Kaja, Sesetan dalam menyambut pelaksanaan hari raya Nyepi. Permainan ini, seperti dalam gambar 1, berupa permainan 
saling tarik menarik antara pemuda dan pemudi asli warga Banjar Kaja, Sesetan dan permainan ini tidak diperkenankan melibatkan kalangan (warga) dari luar banjar.

Sebelum tahun 1980-an, tradisi Omed-omedan dilaksanakan tepat pada hari raya Nyepi tepatnya pada sore hari, di mana pada saat itu masyarakat belum melaksanakan ajaran agama dengan baik. Namun setelah tahun 1980-an, Parisada Hindu Dharma Indonesia melakukan pengaturan, penataan, dan pembinaan pada umat Hindu maka pelaksanaan tradisi Omed-omedan dilakukan keesokan harinya tepatnya pada hari Ngembak Geni (Munggah, 2008: 2). Diungkapkan dalam beberapa wawancara dengan awak media maupun dalam pemaparan di depan sekaa truna (pemuda-pemudi) Banjar Kaja, Sesetan, I Gusti Ngurah Oka Putra (selaku penglingsir Puri Oka) seperti dipaparkan oleh Munggah (2008: 32), menceritakan tentang tradisi ini dimulai pada saat seorang penglingsir Puri Oka yang bernama Anak Agung Made Raka yang dijuluki Ida Bhatara Kompiang mengalami sakit keras sampai tidak mampu beranjak dari tempat tidur. Beliau berpesan kepada masyarakatnya untuk tidak menjenguknya dan tidak untuk melakukan kegaduhan di depan Puri. Mendengar hal tersebut, beberapa warga merasa kecewa akan larangan yang dibuat oleh penglingsir Puri Oka tersebut. Pada hari Raya Nyepi, mereka berusaha melanggar larangan tersebut dan tetap melaksanakan tradisi Omed-omedan. Akhirnya Omed-omedan pun ramai seperti sediakala sehingga menimbulkan kegaduhan di depan Puri. Mendengar hal tersebut penglinsir Puri tersebut berniat untuk menegur beberapa warga yang telah melanggar larangannya, namun sesampainya di depan Puri dengan diantarkan pihak keluarga-beliau merasa sakitnya berangsur-angsur membaik dan bahkan sembuh. Atas dasar itulah beliau meminta untuk melanjutkan tradisi ini seperti sedia kala. Tradisi Omed-omedan ini diyakini memiliki nilai sakral dan sangat erat kaitannya dengan dewa yang dipuja di Banjar Kaja Sesetan (sasuhunan). Dengan nilai kesakralannya, jika tradisi ini tidak diselenggarakan maka dipercaya akan menimbulkan musibah atau bahaya yang mengancam banjar tersebut.

Seperti yang telah diungkap diawal bahwa tradisi ini sempat pula mengalami perbaikan nama. Dikatakan perbaikan karena nama yang dikenal diawal, yaitu Medmedan, tidak mengalami perubahan secara signifikan hanya saja mengalami pelurusan bahasa agar memiliki pengertian atau pemahaman yang baik dalam penggunaan bahasa (Bali). Pada awal tradisi ini dikenal dengan nama Med-medan namun seiring perkembangan jaman dan mulai dikenalnya tradisi ini secara luas maka pada tahun 2000-an nama tradisi ini disempurnakan menjadi Omed-omedan. Seperti diungkap oleh Munggah (2008: 2) yang mengutip dari Kamus Bali-Indonesia, kata dasar maOmed-omedan adalah omed. Kata omed diulang menjadi omed-omed mendapat konfiks ma - an sehingga menjadi maomeed-omedan yang artinya bertarik-tarikan (dalam kegitan ini tanpa alat apapun alias menggunakan tangan).

Pelaksanaan tradisi Omed-omedan yang pada awalnya merupakan sebuah tindakan spontan dari masyarakat Banjar Kaja Sesetan, namun dalam perkembangannya pelaksanaan tradisi ini sudah lebih terkoordinasi. Jika sebelumnya pelaksanaan tradisi ini dilaksanakan (dikoordinasikan) oleh Banjar Adat melalui prajuru adatnya, maka pada medio 1990-an pelaksanaan tradisi ini dikelola oleh Sekaa Teruna. Penggunaan dana penyelenggaraan tradisi yang pada awalnya menggunakan kas banjar namun dalam perkembangannya pada saat pengelolaan diambil alih oleh Sekaa Teruna maka dana penyelenggaraan diperoleh melalui bantuan pihak luar 
(sponsor). Hal ini dimungkinkan karena pihak Sekaa Teruna belum memiliki kemampuan finansial (dana) seperti banjar adat dan penyelenggaraan harus dikemas dengan baik karena tradisi ini sudah semakin dikenal masyarakat luas. Pada tahun 2009, tradisi ini dikemas kembali dengan nama Sesetan Heritage Omed-omedan Festival dengan harapan agar semakin dikenal dan tentunya dimasukkan dalam kalender pariwisata kota Denpasar.

Pelaksanaan tradisi Omed-omedan yang kemudian menjadi Sesetan Heritage Omed-omedan Festival (SHOOF) sangat berbeda dengan pelaksanaan sebelumnya. Festival ini menambahkan kegiatan peken paiketan dan atraksi budaya dalam rentetan acara dengan tradisi Omed-omedan sebagai puncak acara pada festival tersebut, hal ini mengakibatkan bertambahnya durasi penyelenggaraan tradisi yang semula berlangsung hanya 2 jam menjadi 8 jam pada saat hari Ngembak Geni. Panjangnya durasi penyelenggaraan tentu saja berimbas pada tingginya biaya kegiatan, namun hal ini disiasati dengan menggandeng sponsor baik dari pihak swasta maupun pihak pemerintahan Kota Denpasar. Berubahnya pelaksanaan tradisi Omed-omedan menjadi sebuah festival memungkinkan tradisi ini dimasukkan ke dalam kalender pariwisata Kota Denpasar sehingga memperoleh pendanaan tetap dari pemerintah.

\section{PEMBAHASAN}

Dalam industri budaya, ideologi kapitalis sering menghegemoni masyarakat tanpa disadari, begitupula yang terjadi pada masyarakat Banjar Kaja Sesetan selaku penyelenggara tradisi Omed-omedan. Transformasi sebuah tradisi yang pada awalnya dilaksanakan secara spontanitas oleh masyarakat menjadi sebuah festival menunjukkan bahwa industri budaya dengan ideologi kapitalisnya mampu mempengaruhi sebagian besar masyarakat untuk menyetujui pelaksanaan tradisi ini dikemas menjadi sebuah festival. Masyarakat Banjar Kaja Sesetan merasa membutuhkan sebuah model baru dalam pelaksanaan tradisi ini sehingga memiliki nilai jual lebih dan mampu lebih dikenal dibamding sebelumnya. Hal ini sesuai dengan ungkapan Strinatri (2007: 73) bahwa Industri budaya membentuk selera dan kecendrungan massa sehingga mencetak kesadaran palsu dengan cara menanamkan keinginan mereka atas kebutuhan-kebutuhan palsu.

Secara tidak langsung dengan berubahnya tradisi Omed-omedan menjadi sebuah festival tentunya diperlukan kemasan-kemasan yang dianggap mampu menarik massa dalam jumlah banyak. Kemasan ini dapat berupa beberapa acara tambahan serta promo-promo melalui media komunikasi visual. Adanya kemasankemasan ini sudah tentunya membuat sebuah festival memiliki keseragaman antara satu dengan lainnya, seperti diiungkap oleh Strinatri (2007: 110) yang menyatakan bahwa kekuatan ideologi industri budaya sudah sedemikian rupa hingga konformitas (keseragaman) menggantikan kesadaran. Kesadaran-kesadaran palsu ini secara tidak langsung mengikis autentisitas dari festival (tradisi) tersebut. Hal ini juga terlihat pada Sesetan Heritage Omed-omedan Festival dengan berbagai atraksi budaya dan peken paiketan sebagai tambahan acara dalam festival menunjukkan adanya keseragaman dengan beberapa festival budaya sejenis (Sanur Village Festival dan Denpasar Festival).

Penggunaan bantuan dana dari luar (sponsor) tentunya juga mempengaruhi bentuk-bentuk penyelenggaraan tradisi ini. Para pendukung dana (sponsor) dengan 
baik hati menawarkan bantuan dana dengan imbalan pencantuman nama perusahaan atau produk di beberapa atribut dalam festival tersebut, dari bentuk yang paling sederhana yaitu mencantumkan nama-nama perusahaan atau produk perusahaan pada pakaian ( $t$-shirt) peserta tradisi Omed-omedan seperti terlihat pada gambar 2 sampai dengan branding menyeluruh dari festival tersebut (media baliho, gate festival, dan backdrop) seperti terlihat pada gambar 3. Namun kebaikan hati para pendukung acara (sponsor)

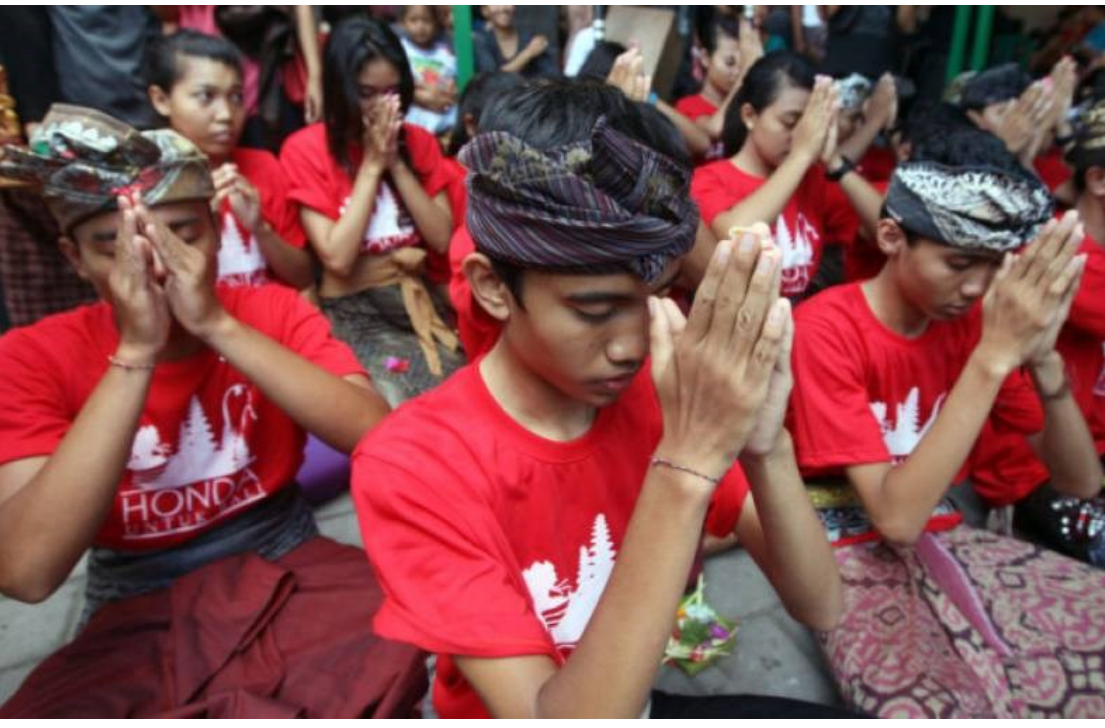

Gambar 2. Pencantuman sponsor di media t-shirt di Sesetan Heritage Omed-omedan Festival

Sumber: www.static.gulfnews.com tersebut diasumsikan hanyalah sebuah kepalsuan di mana sejatinya pihak sponsor tersebut berusaha mengambil keuntungan dengan melakukan promosi produknya dengan biaya murah dan berharap memperoleh keuntungan yang maksimal. Penggunaan media-media promo untuk mempromosikan festival tersebut semakin mempertegas asumsi tersebut.

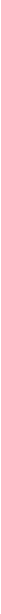

Gambar 3. Branding Sesetan Heritage Omed-omedan Festival Sumber: repro penulis

Bentuk-bentuk penyantuman nama-nama sponsor tersebut merupakan sebuah bentuk hegemoni kelas-kelas dominan (perusahaan) dengan kelas bawah (masyarakat) yang tanpa sadar menyetujui ide-ide dari kelas dominan tersebut. Hal ini dibuktikan dengan tidak adanya pertentangan dari masyarakat Banjar Kaja selaku kelas bawah untuk mencantumkan nama-nama sponsor tersebut pada beberapa atribut festival. Penguasaan-penguasaan ini dilakukan menggunakan ideologi kapitalis yang secara tidak langsung telah mengkomodifikasikan tradisi Omed-omedan, di mana komodifikasi sendiri menurut Barker (2014: 41) dipahami sebagai sebuah barang yang tujuan utama keberadaannya adalah untuk dijual di masyarakat. Barang yang 
dimaksud disini dapat berupa tradisi Omed-omedan itu sendiri, di mana komodifikasi dari tradisi Omed-omedan ini sendiri terbentuk karena adanya hasrat eksistensi dari masyarakat Banjar Kaja, Sesetan.

Peken paiketan sebagai salah satu acara dalam festival merupakan salah satu bentuk komodifikasi. Komodifikasi ini terlihat dari adanya pemungutan biaya oleh pihak penyelenggara dengan alasan penyediaan tempat dan perlengkapan untuk beberapa dagang yang akan ikut dalam festival tersebut. Biaya para peserta peken paiketan dari tahun ke tahun mengalami peningkatan namun tidak mengurangi animo para peserta yang akan mengikuti festival tersebut. Komodifikasi berikutnya adalah penambahan atraksi-atraksi budaya yang selalu berbeda dari tahun ke tahun, diantaranya ; mengundang band-band pop Bali, parade budaya, dan lomba-lomba seni. Atraksi atau hiburan ini tidak lebih hanya ingin memberikan kepuasan kepada masyarakat yang menonton festival (tradisi) tersebut dan tentu saja atraksi tersebut tidak memiliki nilai sakral sedikit pun, kemudian pada prosesi tradisi Omed-omedan itu sendiri, jika pada awalnya prosesi dimulai dengan sembahyang bersama untuk memperoleh keselamatan dan setelah itu permainan Omed-omedan dapat dilangsungkan, namun sejak dikemas menjadi sebuah festival prosesi ditambahkan dengan memberikan atraksi tari-tarian sebagai pembuka permainan (gambar 4).

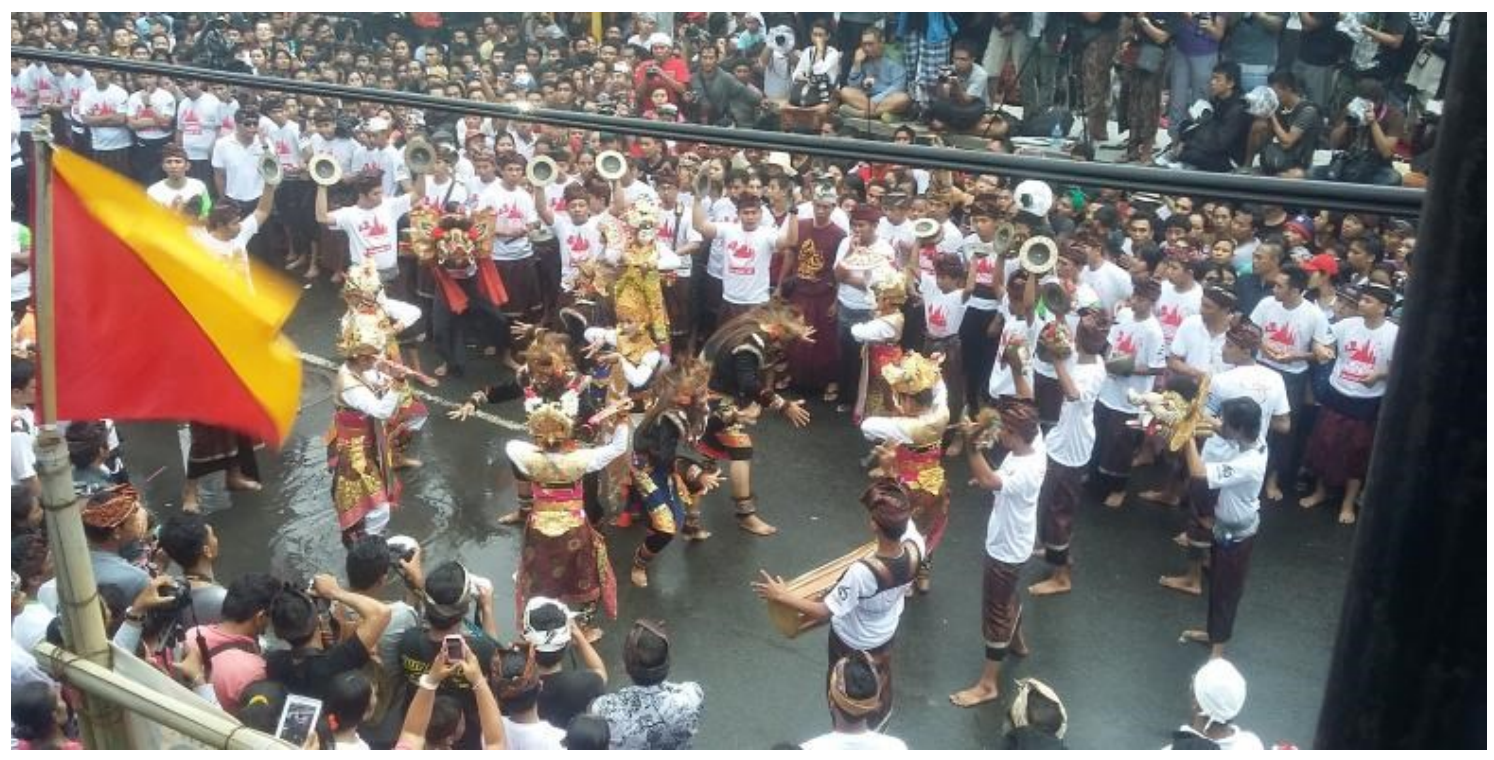

Gambar 4. Atraksi seni tari sebelum prosesi tradisi Omed-omedan Sumber: www.bali.tribunews.com

Atraksi atau hiburan ini tidak lebih hanya ingin memberikan kepuasan kepada masyarakat yang menonton festival (tradisi) tersebut dan tentu saja atraksi tersebut tidak memiliki nilai sakral sedikit pun. Dalam Peken paiketan sempat terlihat sebuah stand yang menjual pernak-pernik tradisi Omed-omedan (gambar 5) di mana pernakpernik tersebut mendapat respon yang positif di masyarakat. Hal ini mengasumsikan bahwa tradisi Omed-omedan sudah sangat dikenal kalangan masyarakat luas sehingga memiliki nilai jual ekonomis yang cukup tinggi. Pembelian pernak-pernik (cinderamata) tradisi Omed-omedan ini diasumsikan merupakan sebuah bentuk eksistensi penggunanya atau sebagai bentuk kehadiran masyarakat dalam tradisi tersebut. 


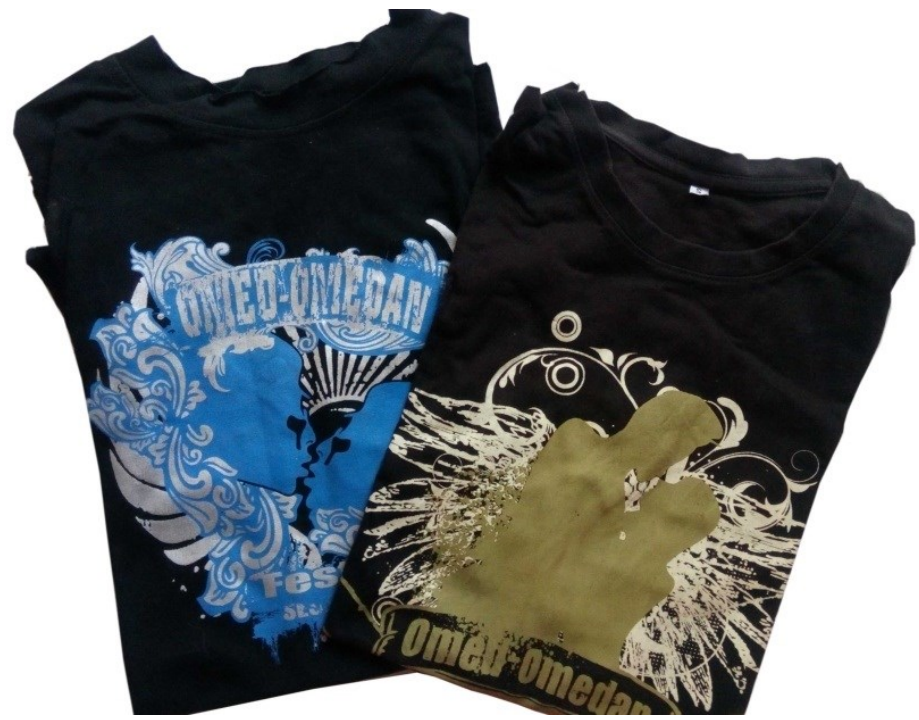

Gambar 5. Salah satu pernak-pernik tradisi Omed-omedan Sumber: repro Jayanegar

Pihak penyelenggara pun tahu betul akan hasrat eksistensi masyarakat pada saat ini, eksistenti ini ditunjukkan dengan mendokumentasikan segala sesuatu yang berhubungan dengan dirinya, baik itu tentang tempat, kegiatan, dan bahkan kondisi emosi. Hal ini berusaha diakomodir oleh pihak penyelenggara dengan membuatkan sebuah panggung khusus dengan latar belakang logo tradisi Omed-omedan yang disertai dengan tampilan salah satu sponsor (gambar 6). Masyarakat yang melakukan dokumentasi pada panggung tersebut diyakini sebagai salah satu bentuk bukti kehadiran dalam festival tersebut.

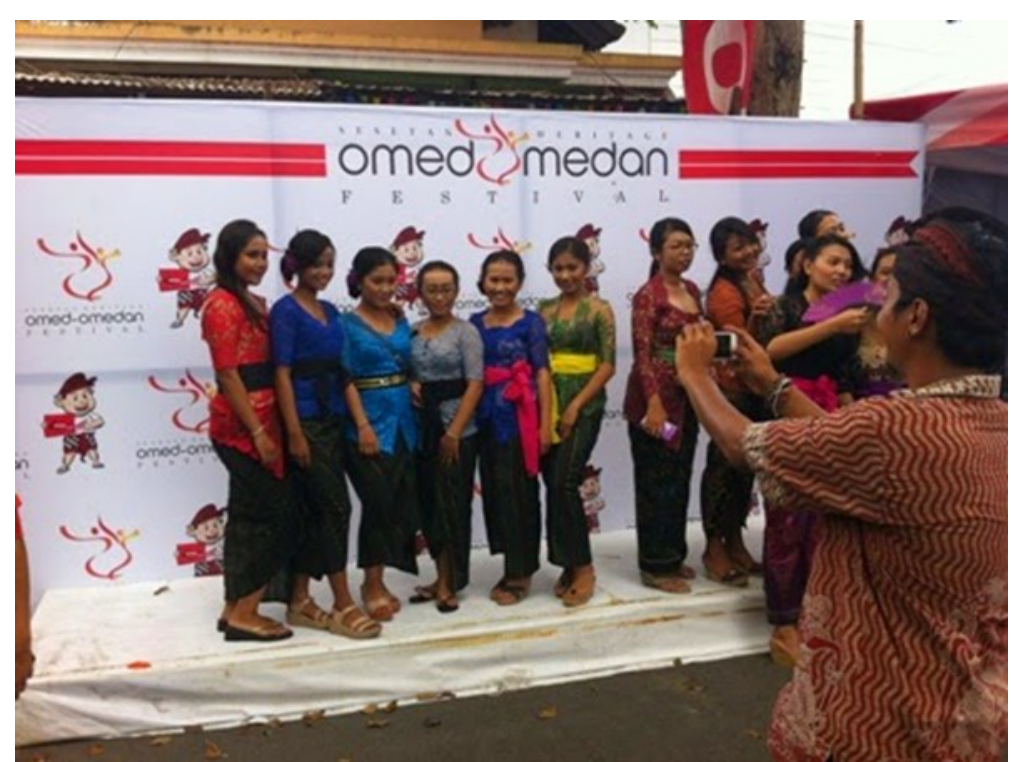

Gambar 6. Panggung khusus dokumentasi pada Sesetan Heritage Omed-omedan Festival. Sumber: www.bali.tribunews.com

\section{SIMPULAN}

Saat sebuah tradisi telah mengalami komodifikasi yang pada akhirnya menjadi sebuah industri budaya, maka masyarakat baik secara individu atau kelompok secara tidak langsung dan tidak sadar telah menjadi bagian dalam struktur budaya yang telah 
dikomersialkan. Industri budaya dengan ideologi kapitalisnya secara tidak sadar telah menghegemoni masyarakat dengan kesadaran-kesadaran palsu yang dijanjikan. Masyarakat Banjar Kaja, Sesetean secara tidak sadar telah terhegemoni oleh ideologi kapitalis sehingga secara tidak sadar telah menyetujui transformasi tradisi dari yang bersifat spontanitas menjadi sebuah festival. Dengan alasan kemajuan jaman dan pariwisata, tradisi ini dianggap memiliki nilai jual tinggi secara ekonomis sehingga sudah selayaknya dijadikan sebuah festival budaya. Industri budaya memang tidak menghilangkan nilai sakral pada tradisi ini namun dengan berubah menjadi sebuah festival dengan berbagai kemasan-kemasan yang memuaskan masyarakat yang hadir mengakibatkan hilangnya autentisitas tradisi tersebut, telah terjadi penyeragaman secara tidak sadar pada pelaksanaan tradisi ini.

Banyak hasrat yang bermain dalam penyelenggaraan festival tersebut, hasrat ekonomi yang paling menonjol dalam hal ini. Mengikutsertakan beberapa perusahaan dan kemudian pemerintah Kota Denpasar dalam pendanaan merupakan salah satu bentuk hasrat tersebut. Kelas-kelas atas (perusahaan) dengan kekuatan modalnya mampu secara tidak langsung dan tidak sadar telah mampu memaksakan kehendaknya dalam festival ini. Kehendak-kehendak ini secara tidak sadar disetujui oleh masyarakat Banjar Kaja, Sesetan sebagai sebuah kewajaran dan memang sepatutnya terjadi. Hasrat ekonomi lainnya dapat terlihat dari dijualnya stand-stand dagang pada peken paiketan di festival tersebut. Tradisi Omed-omedan dengan nilai jual ekonomi yang cukup tinggi mampu menghipnotis masyarakat pedagang berebut untuk memperoleh bagian dalam festival tersebut.

Hasrat eksistensi pun terlihat dalam penyelenggaraan festival ini, dengan kehadiran perusahaan-perusahaan dengan kekuatan modalnya, pemerintah melalui walikota yang sempat membuka festival dan sudah tentunya animo masyarakat yang cukup tinggi untuk menyaksikan festival ini sudah barang tentu menghadirkan sebuah kepuasan palsu bagi masyarakat Banjar Kaja, Sesetan. Penyelenggaraan festival ini dengan berbagai macam media promosi yang digunakan diasumsikan telah mampu menempatkan Banjar Kaja, Sesetan beserta warga masyarakatnya di dalam peta dan sebagai sebuah destinasi baru pariwisata di Kota Denpasar.

\section{DAFTAR PUSTAKA}

Barker, Chris. 2014. Kamus Kajian Budaya, PT Kanisius, Yogyakarta

Cahyadinata, I Putu Andrew Aditya. 2019. "Perspektif Sosio-Budaya dan Religius rerhadap Tradisi Med-Medan Di Banjar Kaja, Desa Pakraman Sesetan, Kota Denpasar, Bali", https: //ejournal.undiksha.ac.id. Diakses tanggal 15 Februari 2019.

Disbud. 2016. Tradisi Med-Medan di Banjar Kaja Sesetan, Deskripsi Sejarah, Struktur, Fungsi dan Makna. Denpasar: Dinas Kebudayaan Kota Denpasar.

Heryanto, Arie. 1997. "Dinamika Budaya dalam Kapitalisme Indonesia", dalam Ibrahim (ed), Lifestyle Ecstasy: Kebudayaan Pop dalam Masyarakat Komoditas Indonesia. Yogyakarta: Jalasutra.

Mahardika, I Wayan Didik Roy. 2019. "Festival Heritage Omed-omedan Sebagai Daya Tarik Wisata di Sesetan, Denpasar", Jumpa Jurnal Master Pariwisata, Vol. 1 No. 2, 117-133, https: //ojs.unud.ac.id/index.php/jumpa. Diakses tanggal 15 Februari 2019.

Munggah, I Made. 2008. Med-Medan Tradisi Unik dari Sesetan. Denpasar: Pustaka Bali Post.

Strinatri, Dominic. 2007. Popular Culture Pengantar Menuju Teori Budaya Populer. Yogyakarta: Pustaka Promothea.

Sutrisno, Mudji; Putranto, Hendar. 2005. Teori-teori Kebudayaan. Yogyakarta Kanisius. 